\title{
EDITORIAL
}

\section{DOSSIÊ: \\ IMPACTOS E REPERCUSSÕES SOCIOAMBIENTAIS DE EMPREENDIMENTOS NA PAN-AMAZÔNIA}

Com o presente editorial, lançamos o volume 06 da InterEspaço: Revista de

Geografia e Interdisciplinaridade. Esta edição, organizada na forma de um dossiê, contribui para a análise dos impactos e das repercussões socioambientais da implantação de grandes projetos de investimentos $(\mathrm{GPI})^{1}$ na Pan-Amazônia. Contempla uma diversidade de temas e variedade de abordagens presentes na ciência geográfica e em suas interfaces interdisciplinares.

Ao tratarmos da referida temática, de forma especial, procuramos, identificar traços perenes nas faces dos modelos e estilos de desenvolvimento regional induzidos pelas políticas e ações públicas do estado brasileiro na sucessão histórica dos últimos 40 anos na Amazônia brasileira.

Bertha Becker (2007, p. 126) ${ }^{2}$, enfatiza que o modelo exógeno teve maciça predominância histórica no âmbito das políticas de desenvolvimento na região. Trata-se de um modelo ${ }^{3}$ baseado numa visão externa ao território e que privilegia as relações de dependência com as metrópoles, com os grandes centros motores da economia global.

Nesses termos, no contexto da globalização, e de uma nova configuração dos mecanismos de acumulação do capital (HARVEY, 2018) ${ }^{4}$, uma nova geografia econômica emerge, a partir de processos concomitantes de desconcentração do processo produtivo e

\footnotetext{
${ }^{1}$ Segundo Daniel Hiernaux Nicolas, Grandes projetos de investimentos "deben ser entendidos como procesos de largo plazo, por los cuales un actor económico, generalmente, el Estado, realiza inversiones masivas em obras de infraestructura y/o en producción directa, con una fuerte concentración en algun punto del territorio. En términos generales, se ha observado que las inversiones se concentran en espacios con caacteristicas preindustriales, por lo que se observan transformaciones radicales de las condiciones demográficas, económicas y territoriales en torno del proyecto"( 1989, p. 248 e 349). Hiernaux, N. D. Grandes proyectos de inversions y el desarrollo regional. El caso Mexicano. In: BRUNSTEIN, F.; ROFMAN, A.; LAURELLI, E.; VIDAL, A. (Comp.). Grandes inversiones públicas y el espacio regional. Ediciones CEUR, 1989.

${ }^{2}$ BECKER, B. Amazônia: Geopolítica na virada do III milênio. Rio de Janeiro: Garamond, 2007 [1 ${ }^{a}$ ed. 2004].

${ }^{3}$ BRANDÃO, C. Visões teóricas sobre desenvolvimento regional e a questão das escalas (mundial, nacional, subnacional e local) nas políticas regionais contemporâneas. Material didático do curso “Territorialidade e Políticas Públicas no Brasil”. ENAP, Brasília, 2 de maio de 2011. 25 p.

${ }^{4}$ HARVEY, D. A loucura da razão econômica: Marx e o capital no século XXI. São Paulo: Boitempo, 2018.
} 
InterEspaço: Revista de Geografia e Interdisciplinaridade

|Editorial: Impactos e repercussões socioambientais de empreendimentos na Pan-Amazônia|

| Gilberto de Miranda Rocha |

de centralização do capital, resultando na "relocalização" dos investimentos e das atividades produtivas.

Para Zhoury e Oliveira Apud Chesnais (2007) ${ }^{5}$, longe de produzir um cenário de integração entre as diversas regiões do globo, a lógica seletiva do capital atinge de maneira distinta determinadas regiões e camadas sociais, resultando numa distribuição desigual dos impactos e riscos decorrentes das atividades produtivas.

Deve-se destacar o fato de que, em regiões periféricas, a implantação de grandes projetos de investimentos decorrentes das referidas dinâmicas, transformam profundamente as formas de uso e ocupação do território, o modo de vida das populações regionais, o aporte demográfico, a rede de cidades e o sistema de povoamento e, rompe, em certo sentido, com os circuitos de acumulação e de desenvolvimento historicamente construídos, redefinindo a realidade regional (ROCHA, 2006) ${ }^{6}$.

Os grandes projetos são assim "geradores de novas regiões" (VAINER; ARAÚJO, 1992, p. 31 ${ }^{7}$. Os autores enfatizam que essas alterações recriam a região a partir dos grandes projetos de investimento. Em outras palavras, os grandes projetos são portadores de um grande potencial de organização e transformação dos espaços, um grande potencial para decompor e compor espaços regionais.

Eis, neste número, da presente revista científica, múltiplas expressões desses processos, focalizando as repercussões socioambientais na Amazônia.

André Cutrim Carvalho, revisita as origens políticas e institucionais das transformações nas formas de apropriação e uso do espaço regional, em especial no Estado do Pará no artigo EXPANSION STRATEGIES AND CAPITALIST DEVELOPMENT ON THE FRONTIER OF PARÁ: an analysis of the 1966 "Operation Amazon”. A institucionalização da "Operação Amazônia", é demonstrada como uma estratégica, um alicerce da dinâmica de penetração, ocupação e avanço do capital no território estadual desde o final da década de 1960, desdobrando-se uma série de ações políticas de suporte a abertura regional.

Luiz Ricardo Cavalcante, resgata a importância das zonas econômica especial no desenvolvimento regional, por meio do artigo ZONA FRANCA DE MANAUS: uma revisão sistemática de impactos. Criada ainda no período militar, em 1967, a ZFM

\footnotetext{
5 ZHOURY, A.; OLIVEIRA, R. Desenvolvimento, conflitos sociais e violência no Brasil Rural: o caso das usinas hidrelétricas. Ambiente \& Sociedade, Campinas v. 10, n. 2 p. 119-135, jul./dez. 2007.

${ }^{6}$ ROCHA, G. M. Todos Convergem para o Lago: hidrelétricas, municípios e territórios na Amazônia. Belém do Pará: NUMA/UFPA, 2006.

${ }^{7}$ VAINER, C. B.; ARAÚJO, F. G. B. Grandes Projetos Hidrelétricos e Desenvolvimento Regional. Rio de Janeiro: Centro Ecumênico de Documentação e Informação, 1992. v. 1.
} 
InterEspaço: Revista de Geografia e Interdisciplinaridade

|Editorial: Impactos e repercussões socioambientais de empreendimentos na Pan-Amazônia|

| Gilberto de Miranda Rocha |

repercutiu no crecimento espacial, impactando de forma positica e negativa no desenvolvimento urbano da cidade e seu entorno.

Norbert Fenzl, Daniel Sombra, Otávio do Canto, André Farias e Fernanda Nascimento no artigo OS 'GRANDES PROJETOS' E O PROCESSO DE URBANIZAÇÃO DA AMAZÔNIA BRASILEIRA: consequências sociais e transformações territoriais, apresentam uma síntese da relação entre os "Grandes Projetos" e o processo de urbanização da Amazônia brasileira e apontam para as consequências sociais e territoriais decorrentes. Além de analisar a origem e o desenvolvimento das grandes contradições e conflitos socioeconômicos que caracterizam as cidades amazônicas, nos convidam para refletir sobre as mudanças no uso da terra, que satisfaz principalmente os interesses dos grandes empreendimentos do agrobusiness da pecuária e da mineração.

Alan Nunes Araújo, Maria Lúcia Brito da Cruz, Christian Nunes da Silva e Amintas Nazareth Rossete, analisam a dinâmica do uso da terra e da cobertura vegetal da bacia hidrográfica do rio Araguari, Amapá, a partir de uma visão integrada no artigo DINÂMICA DA COBERTURA E USO DA TERRA NA BACIA HIDROGRÁFICA DO RIO ARAGUARI (AMAPÁ, AMAZÔNIA, BRASIL). Utilizando geotecnologias e interpretação de imagens de satélites, em espaço temporal siginificativo, 1995 a 2017, foi possível a classificação do uso e da cobertura do solo. Os resultados demonstraram que a bacia hidrográfica do rio Araguari, apresenta grandes transformações desde o ano de 1995, principalmente no médio e baixo curso, reflexos dos intensos processos de exploração de seus recursos naturais e impulsionados pela exploração hidrelétrica.

Gilberto de Miranda Rocha, Marjorie Barros Neves e André Farias, realizam reflexões sobre a relação entre a implantação de grandes projetos de investimento (GPI) na Amazônia em especial, os grandes projetos hidrelétricos e os espaços locais. No artigo INSERÇÃO REGIONAL DA USINA HIDRELÉTRICA BELO MONTE E A GOVERNANÇA TERRITORIAL, destacam a literatura técnica e científica sobre as hidrelétricas, mostrando que ela tem revelado não somente a natureza impactante das UHE, evidenciando as transformações territoriais delas advindas como também o caráter de enclave e, mesmo, de empreendimentos de múltiplos propósitos no que respeita ao desenvolvimento regional. A natureza de enclave aponta a evidente subordinação do conjunto de interesses regionais ao cumprimento de um fim único: a geração de energia elétrica para abastecer demandas espacialmente distantes e potencializar os processos de acumulação de capital extra-regionais, com mínimos benefícios para a região de implantação. 


\section{InterEspaço: Revista de Geografia e Interdisciplinaridade}

|Editorial: Impactos e repercussões socioambientais de empreendimentos na Pan-Amazônia|

| Gilberto de Miranda Rocha |

José Aldair Pinheiro, Aumeri Carlos Bampi e Carlos Alberto Franco da Silva, no artigo O PROJETO DE ASSENTAMENTO CONJUNTO TERRANOVA I NA BORDA MERIDIONAL DA AMAZÔNIA MATO-GROSSENSE: efeitos territoriais da ocupação, destacam os assentamentos rurais como modelo de ocupação planejada da terra na regação e suas repercussões ambientais. O estudo analisa a relação sociedade/natureza e os efeitos territoriais decorrentes do assentamento via colonização oficial-particular na Amazônia, no Projeto Terranova I, na região norte de Mato Grosso. Situado no âmbito das políticas nacionais integracionistas da década de 1970, surgiu como resposta às demandas de campesinos gaúchos e sem-terra, em face dos problemas da modernização da agricultura sulista. Passadas décadas de apropriação da terra com intensa degradação e graves implicações ecológicas e socioeconômicas. O assentamento rural revelou insustentabilidade das práticas produtivas e problemas de fixação do camponês à terra.

Allison Bezerra Oliveira, Diego Armando Souza Paz e Keilha Correia da Silveira, na contraposição ao modelo de assentamentos rurais, analisam as transformações recentes no uso da terra frente o avanço da silvicultura do eucalipto em quatro municípios do oeste maranhense: Imperatriz, Cidelândia, São Pedro d’Água Branca e Vila Nova dos Martírios. E como tal, discute o processo de inserção desta cultura no estado e algumas das transformações decorrentes deste avanço no artigo EXPANSÃO DA SILVICULTURA DO EUCALIPTO E TRANSFORMAÇÕES NO USO DA TERRA EM MUNICÍPIOS DO OESTE MARANHENSE.

Em perspectiva semelhante, a análise da expansão do agronegócio na região, Gabriel Nava Lima e Ademir Kleber Morbeck de Oliveira, destacam o suporte de investimentos do Estado brasileiro na área de infraestrutura e de financiamentos de empreendimentos. O artigo IMPLANTAÇÃO DA FÁBRICA DE CELULOSE DA SUZANO NO SUDOESTE MARANHENSE À LUZ DOS PRINCÍPIOS DO DESENVOLVIMENTO SUSTENTÁVEL, destaca que tais ações estatais proporcionaram a criação de condições para a expansão do agronegócio e surgimento de empreendimentos industriais, em detrimento do extrativismo e da agricultura de subsistência na região centro-sul do estado do Maranhão.

Eder Carvalho dos Santos e Antônio Cordeiro Feitosa, no artigo ANÁLISE GEOAMBIENTAL E PERCEPÇÃO DE UNIDADES DE PAISAGEM NO MUNICÍPIO DE GRAJAÚ-MARANHÃO abordando as transformações territoriais no estado do Maranhão, em especial no município de Grajaú no contexto da reestruturação do seu espaço econômico maranhense, a partir da segunda metade do século XX, realizam 
InterEspaço: Revista de Geografia e Interdisciplinaridade

|Editorial: Impactos e repercussões socioambientais de empreendimentos na Pan-Amazônia|

| Gilberto de Miranda Rocha |

análise geoambiental dos elementos orientadores de mudanças na paisagem, enriquecendo a discussão sobre os processos de formação do espaço territorial municipal.

Tarsis Esaú Gomes Almeida, Maria do Socorro Almeida Flores e Mário Vasconcellos Sobrinho, no artigo MAPEAMENTO DE RISCO DE DESASTRE POR INCÊNDIO FLORESTAL NA AMAZÔNIA: uma abordagem multifatorial no município de Moju (PA), dedicam atenção aos riscos da difusão de queimadas e focos de calor no território paraense, No estado do Pará o município de Moju é um dos que apresentam a maior quantidade de focos de calor conforme dados oficiais. Note-se que a base de suas atividades econômicas são a agricultura familiar e as plantações de dendê e coco-da-baía, diante disso propôs-se questionar sobre o risco não apenas da existência de incêndios florestais, mas da magnitude das consequências socioeconômicas deles.

João Santos Nahum, Leonardo de Sousa Santos e Cleison Bastos dos Santos no artigo USOS E ABUSOS DOS RECURSOS HÍDRICOS PELA DENDEICULTURA NA AMAZÔNIA PARAENSE sustentam que a dendeicultura atua como agrohidronegócio na Amazônia paraense. Enquanto produção do espaço do capital, ela usufrui de recursos hídricos a partir da apropriação da terra, confundindo direito de propriedade com direito à propriedade. Por agrohidronegócio compreende-se uma categoria analítica das tensões, disputas e conflitos territoriais decorrentes da ação do capital para usar e se apropriar dos corpos hídricos no espaço. Entende-se por dendeicultura as determinações espaciais que possibilitam o cultivo do dendezeiro nesta fração da Amazônia e por meio destas reorganizar a paisagem, a configuração espacial e a dinâmica social dos lugares sob sua influência. Está-se diante de prática que produz uma representação de espaço onde esse vetor econômico silencia suas responsabilidades, impactos e riscos ambientais e se apresenta como recuperador de áreas degradadas econômica e ambientalmente, gerador de empregos, renda e inclusão social.

Aquiles Simões e Matheus Benassuly, em artigo de grande interesse EFEITOS SOCIOAMBIENTAIS DA HIDRELÉTRICA DE TUCURUÍ EM AÇAIZAL, BAIÃOPA: VIOLAÇÃO DE DIREITOS, CONFLITOS E RECOMPOSIÇÃO TERRITORIAIS, demonstram como os efeitos decorrentes da construção da Usina Hidrelétrica Tucuruí incidiram sobre o modo de vida ribeirinho, ao analisarem uma comunidade de pescadores estabelecidos à jusante da barragem, no município de Baião, Estado do Pará. A construção da barragem incidiu diretamente sobre os direitos daquela população, estimulou conflitos e tem colocado em questão a manutenção dos modos de reprodução dos ribeirinhos, traduzindo-se em processos de desterritorialização e reterritorialização. A ação local, reativa, dos pescadores daquele lugar, expressa a 
| Gilberto de Miranda Rocha |

necessidade de reparação dos direitos que vêm sendo violados pela ação territorializadora do empreendimento.

Cristiano Quaresma de Paula e Christian Nunes da Silva, também demonstram efeitos e impactos socioambientais sobre os territórios de pescadores artesanais. No artigo, DISPUTAS NOS TERRITÓRIOS DA PESCA ARTESANAL BRASILEIRA COMO EXPRESSÃO DA DIALÓGICA ENTRE TERRITÓRIO E AMBIENTE, analisam a partir de múltiplas situações vivenciadas pelos pescadores nos recantos do país e da Amazônia, em contextos intrarregionais diferenciados, a ameaça permanente da desestruturação de territórios tradicionais da pesca artesanal diante das disputas no território e da precarização das condições ambientais relacionadas, principalmente, à aquicultura, a pesca industrial, a pesca comercial e a geração de energia. As disputas no (e pelo) território correlacionam os impactos ambientais e os conflitos territoriais, levando à tendências de colapso dos estoques pesqueiros e de desterritorialização dos pescadores artesanais no país.

Em síntese, são diversos estudos que, certamente, irão contribuir para elucidar muitas questões importantes sobre a persstência do avanço e expansão de atividades econômicas novas e sua inserção tanto nas estruturas socioespaciais quanto nas estruturas ambientais regionais e locais.

Boa leitura a todos!

Belém, 10 de novembro de 2020

\section{Prof. Dr. Gilberto de Miranda Rocha}

Professor Titular da Universidade Federal do Pará

Pesquisador Produtividade PQ2 CNPq. 